\title{
Motivação de ingressantes de licenciatura em química no IFSP
}

Ricardo Castro de Oliveira oliveirarc@ifsp.edu.br orcid.org/0000-0002-5444-6740 Instituto Federal de Educação, Ciência e Tecnologia de São Paulo (IFSP), Catanduva, SP, Brasil

Jackson Gois jackson.gois@unesp.br orcid.org/0000-0001-6863-4032 Universidade Estadual Paulista (UNESP), São José do Rio Preto, São Paulo, Brasil

\section{RESUMO}

Diversos estudos têm evidenciado a importância da motivação na área educacional, no entanto, poucos trabalhos na literatura relacionam a motivação com a formação de professores. Diante da importância dessa temática e da escassez de trabalhos, este estudo tem como objetivo analisar o perfil motivacional dos estudantes ingressantes de 2019 nos cursos de Licenciatura em Química, do Instituto Federal de Educação, Ciência e Tecnologia de São Paulo (IFSP). O referencial teórico utilizado neste trabalho foi a Teoria da Autodeterminação, desenvolvida por Deci e Ryan, que expandiram a compreensão da motivação ao apresentar um continuum, no qual um indivíduo pode transitar pelos diferentes tipos de motivação, desde que satisfaça as necessidades psicológicas básicas: competência, autonomia e pertencimento. Esta pesquisa utilizou o questionário proposto por Guimarães e Bzuneck como instrumento de coleta de dados. A aplicação foi realizada presencialmente por um dos pesquisadores, em horário de aula, e contou com a participação de 176 licenciandos em Química, distribuídos em nove câmpus da Instituição. Os dados foram submetidos a análises estatísticas, tais como média, variância, teste de confiabilidade e análise de correlação e comparados com os trabalhos disponíveis na Literatura. Os resultados evidenciaram um perfil motivacional autodeterminado dos participantes, prevalecendo médias mais elevadas para as categorias motivação extrínseca por regulação integrada e motivação intrínseca. O desenvolvimento de estudos como esse é de grande importância para a área, pois, a partir deles é que podem ser traçados planos e estratégias visando à permanência e o êxito dos estudantes.

PALAVRAS-CHAVE: Formação inicial de professores. Motivação. Teoria da Autodeterminação. Química. 


\section{INTRODUÇÃO}

A palavra motivação é originada do verbo latino movere, que significa moverse, deslocar-se. De forma genérica, Bzuneck (2009) define a motivação como sendo aquilo que move uma pessoa, que a coloca em ação na busca por algo. De forma complementar, Reeve (2006) enfatiza que o estudo da motivação se preocupa com os processos que dão força e direcionam o comportamento dos indivíduos, destacando quatro deles: as necessidades, as cognições, as emoções e eventos externos. Ainda de acordo com o autor, o estudo da motivação busca respostas para duas questões centrais: "o que causa o comportamento?" e "por que o comportamento varia de intensidade"?

É muito comum nos depararmos com reclamações de professores, de que os estudantes não estão interessados, apresentam dificuldades de aprendizagem, ou não estão envolvidos no processo de construção do conhecimento, entre outras problemáticas. Nesse sentido, Corrêa (2009) aponta que os estudos sobre motivação no âmbito escolar fornecem informações importantes para subsidiar o planejamento e a ação do docente. Para Bzuneck (2009), um estudante motivado em sala de aula envolve-se ativamente nas atividades e persiste até o seu êxito, enquanto o estudante com pouca motivação não aplica esforço, realizando apenas o mínimo necessário e desistindo quando as tarefas exigem maior grau de comprometimento.

Os indivíduos podem apresentar dois tipos básicos de motivação: intrínseca e extrínseca. Para Reeve (2006, p.84), “a motivação intrínseca surge espontaneamente das necessidades psicológicas, das curiosidades pessoais e dos esforços inatos para se obter o crescimento". Assim, um indivíduo motivado busca a realização das atividades pelo prazer e pela satisfação de realizá-las e não por recompensas. Esse tipo de motivação é a almejada por educadores, pois resulta em inúmeros benefícios para os indivíduos, entre os quais se destacam a promoção da criatividade, persistência, compreensão conceitual e o seu bem-estar (REEVE, 2006).

Em contrapartida, a motivação extrínseca surge de incentivos e consequências oferecidos ao indivíduo. Para Reeve (2006, p.85), "a motivação extrínseca é um motivo criado pelo ambiente para fazer com que o indivíduo inicie ou persista em uma dada ação". Esse tipo de motivação é muito comum no ambiente escolar: ao fazerem determinadas tarefas os estudantes recebem algo em troca. Nesse caso, fazer a tarefa refere-se ao comportamento desejado, e receber algo é a consequência da ação realizada.

De acordo com Corrêa (2009), os tipos de motivação estão estritamente relacionados com o contexto no qual o indivíduo está inserido e com a natureza da atividade. É importante ressaltar que existem diferentes teorias, cada qual com as suas particularidades para auxiliar na compreensão dos diferentes aspectos envolvidos no processo motivacional. A seguir será apresentada a teoria da Autodeterminação, que serviu de referência no presente estudo. 


\section{TEORIA DA AUTODETERMINAÇÃO}

De acordo com Bzuneck e Guimarães (2010, p.44), "os seres humanos são dotados de natureza ativa, propensos ao desenvolvimento saudável e autorregulação". Essa é a ideia central da Teoria da Autodeterminação, elaborada por Deci e Ryan (1985). No entanto, para que os indivíduos se sintam motivados é imprescindível satisfazer suas necessidades psicológicas básicas sendo elas: autonomia, competência e pertencimento (RYAN; DECl, 2000b).

Reeve (2006) afirma que todo ser humano tem necessidade de autonomia. Ele busca decidir o que fazer, como fazer, quando parar de fazer, o tempo necessário para cada atividade, entre outras decisões baseadas em seus anseios. Para Deci (1980), o comportamento é autônomo (autodeterminado) quando nossos desejos conduzem a tomada de decisões.

A competência é outra importante necessidade psicológica do ser humano. Para Reeve (2006, p.73) ela "fornece uma fonte inerente de motivação, capaz de fazer as pessoas buscarem algo e se esforçarem para alcançar o que for necessário para dominar desafios em um nível ótimo". Para o autor, o indivíduo anseia desenvolver suas habilidades, aumentar sua capacidade e potencial, sendo uma busca constante por resultados satisfatórios. É muito gratificante para o indivíduo quando ele se sente capaz de desenvolver com êxito uma determinada tarefa.

A terceira necessidade psicológica é o pertencimento. Para Reeve (2006) todo indivíduo almeja ter amizades, um bom convívio com as pessoas, com grupos, organizações e com a comunidade. Em geral, os indivíduos não gostam de viver isoladamente, sem interação com outras pessoas.

Levando em consideração a importância das necessidades psicológicas básicas no processo motivacional, Ryan e Deci (2000a) expandiram a compreensão da motivação ao propor um continuum de Autodeterminação, representado na Figura 1.

Figura 1 - Continuum de Autodeterminação com os diferentes tipos de motivação

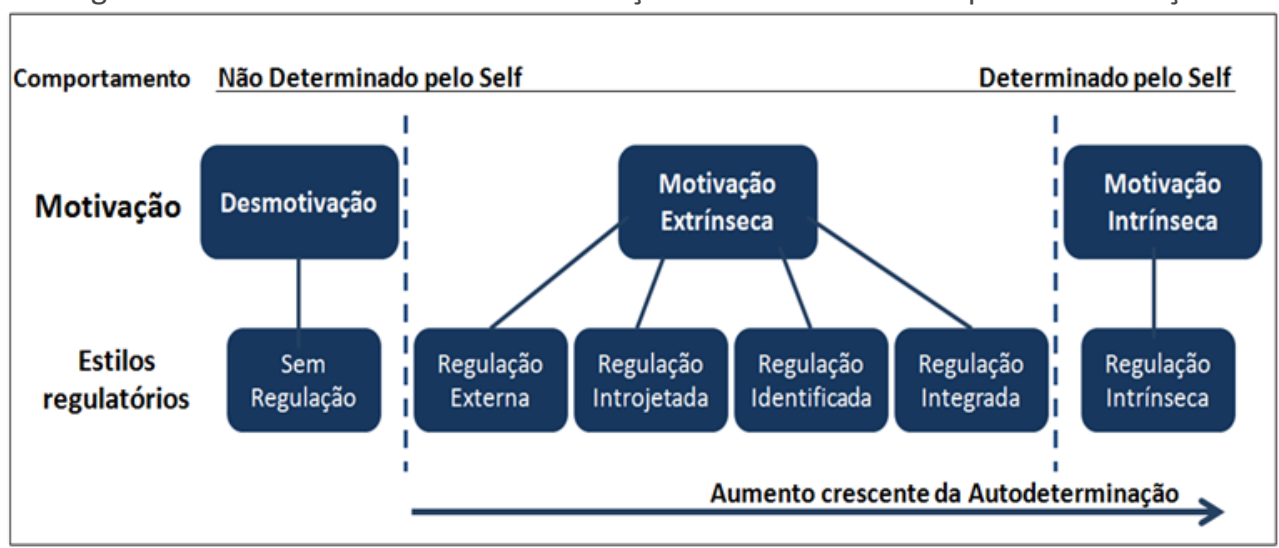

Fonte: Adaptado de Ryan e Deci (2000a).

Para Ryan e Deci (2000b), a motivação pode ser classificada em desmotivação, motivação extrínseca e motivação intrínseca. A desmotivação pode ser caracterizada pela falta de interesse em agir. Mesmo na presença de recompensas, o indivíduo não apresenta intenção de realizar a tarefa. 
A partir da apresentação do continuum de Autodeterminação, a motivação extrínseca passou a ser subdividida, de acordo com os estilos regulatórios em: Motivação Extrínseca por Regulação Externa, Motivação Extrínseca por Regulação Introjetada, Motivação Extrínseca por Regulação Identificada e Motivação Extrínseca por Regulação Integrada.

A motivação extrínseca por regulação externa é a categoria que apresenta o menor grau de motivação autônoma. Nela, os comportamentos são observados para satisfazer uma demanda externa, visando recompensas ou para evitar castigos. Na sequência do continuum tem-se a regulação introjetada, na qual os indivíduos realizam as atividades com a sensação de tensão e pressão visando evitar a culpa ou a ansiedade ou mesmo para satisfazer o seu ego. Trata-se de uma categoria com baixo grau de autodeterminação, porém, maior se comparado à regulação externa (RYAN; DECl, 2000b).

No prosseguimento do continuum aparece a regulação identificada. Trata-se de uma forma autônoma da motivação, sendo considerada como autodeterminada. Nela, o indivíduo identifica-se com a causa e reconhece a sua importância. Porém, a forma mais autodeterminada de motivação extrínseca é a integrada, e ela ocorre quando os comportamentos identificados são assimilados ao self (indivíduo) (RYAN; DECl, 2000b). Para Reeve (2006, p. 99), "quanto mais a pessoa integra maneiras internalizadas de pensar e de se comportar ao sistema mais amplo do seu self, mais as ações extrinsecamente motivadas tornam-se autodeterminadas".

Por fim, tem-se a motivação intrínseca. Esse tipo de motivação ocorre quando o indivíduo realiza uma tarefa pela satisfação e pelo prazer em executá-la, sem a contrapartida de estímulos externos. Essa é a forma mais autônoma e desejada de motivação, uma vez que ocorre o envolvimento total do estudante na execução da tarefa (RYAN; DECl, 2000b).

Ressalta-se que, dentro desse continuum de motivação, os indivíduos podem transitar entre os diferentes tipos, partindo, por exemplo, da desmotivação para os diferentes tipos de motivação extrínseca e, por fim, a intrínseca. O caminho inverso também pode ocorrer, no qual um estudante pode partir de uma motivação intrínseca até chegar à desmotivação. Para Guimarães e Bzuneck (2008), caminhar em direção às formas mais autônomas ao longo do continuum significa apresentar mais características que se aproximam da motivação intrínseca, conhecida como a forma mais autodeterminada e desejada de motivação. De forma complementar, Reeve (2006) enfatiza que quanto mais autodeterminada for a motivação do indivíduo, mais satisfatórios serão os seus resultados em relação ao desempenho, desenvolvimento social e bem-estar psicológico.

\section{TRABALHOS ENVOLVENDO MOTIVAÇÃO NA LITERATURA}

Em uma revisão de literatura, Bzuneck e Boruchovitch (2003) apontaram que embora o número de pesquisas envolvendo motivação esteja aumentando consideravelmente nos últimos anos, a quantidade de trabalhos ainda é pequena em todos os níveis de escolarização. Essa afirmação também foi defendida por Carvalho, Stanzani e Passos (2017), que investigaram os trabalhos publicados no 
Encontro Nacional de Pesquisa em Educação em Ciências (ENPEC) no período de 2005 a 2015, envolvendo a temática motivação. Os autores apontam que apenas $1,6 \%$ do total de trabalhos pertencem a essa temática, evidenciando pouca representatividade em relação às demais áreas. Além disso, apontam que, dentre os trabalhos que mencionaram motivação, $56 \%$ não apresentaram a definição do conceito, utilizando a expressão para ideias relacionadas ao senso comum. Ainda de acordo esses autores, é necessária uma ampliação dos estudos sobre motivação para a compreensão do cenário educacional visando melhorias na Educação.

Muitos trabalhos na literatura associam o termo motivação a utilização de diferentes recursos didáticos, estratégias de ensino ou a aprendizagem, sendo a maioria relacionada a estudantes do Ensino Médio (LOURENÇO; PAIVA, 2010; CLEMENT, 2013; KASSEBOEHMER; FERREIRA, 2013; SILVA et al., 2015; ROSSIERI, 2017; FABRI; GIACOMINI, 2018; ANDRADE; SILVA, 2018; CATANHO, 2018; PARRA, 2018).

A literatura apresenta trabalhos envolvendo a tradução de escalas de motivação para o cenário nacional. Um deles foi desenvolvido por Sobral (2003), que traduziu a escala elaborada por Vallerand et al. (1992) para avaliar os tipos de motivação, de acordo com a Teoria da Autodeterminação. O autor aplicou esse questionário em 269 estudantes do curso de Medicina da Universidade de Brasília e os resultados evidenciaram a confiabilidade do instrumento para o estudo da motivação de universitários brasileiros.

A partir dos estudos de Sobral (2003), Guimarães e Bzuneck (2008) aprimoraram a escala de motivação acadêmica (EMA). Essa versão contemplou a categoria motivação extrínseca por regulação integrada - que estava ausente no questionário traduzido - e a motivação extrínseca por regulação externa que foi subdividida em duas: Regulação externa por frequência às aulas e Regulação externa por recompensas sociais. Participaram desse estudo 388 estudantes de Ensino Superior de três Instituições do norte do Paraná. Foram realizados testes estatísticos e os resultados evidenciaram índices satisfatórios, sendo recomendado pelos autores como um instrumento confiável para averiguar a motivação de universitários, de acordo com a teoria da Autodeterminação.

Visando analisar o tipo de motivação dentro do continuum, tendo como base a teoria da Autodeterminação, é possível encontrar trabalhos utilizando o questionário traduzido por Sobral (2003), o proposto por Guimarães e Bzuneck (2008), ou mesmo questionários adaptados de um desses autores para atender os objetivos e as demandas de cada contexto.

Souza (2008) desenvolveu uma pesquisa com 347 estudantes do curso de Pedagogia de uma universidade pública do norte do Paraná, envolvendo a Teoria da Autodeterminação e a Perspectiva de Tempo Futuro, que busca elementos para compreender se aquilo que o indivíduo projeta para o futuro interfere nas ações do presente, como maior envolvimento e desempenho satisfatório no curso. 0 estudo evidenciou uma relação positiva entre a perspectiva de tempo futuro e as formas mais autodeterminadas de motivação.

Engelmann (2010) analisou as orientações motivacionais de 192 estudantes do curso de Artes de uma universidade pública do norte do Paraná a partir do tipo de motivação, desempenho acadêmico e a intenção de concluir o curso, tendo 
como base a Teoria da Autodeterminação. A pesquisa evidenciou maiores médias para os tipos mais autônomos de motivação.

Almeida (2012) conduziu um estudo a respeito da motivação dos estudantes no Ensino Superior, assim como dos fatores relacionados à motivação. 0 estudo contou com a participação de 1.269 estudantes de instituições públicas e privadas de diferentes regiões do país, tendo como referencial teórico a Teoria da Autodeterminação. Os resultados evidenciaram maiores médias para os tipos mais autônomos de motivação.

Leal, Miranda e Carmo (2013) realizaram um estudo com o intuito de avaliar a motivação dos estudantes do curso de Ciências Contábeis, pautado na Teoria da Autodeterminação. A pesquisa envolveu 259 estudantes matriculados em todos os períodos e constatou que o nível de autonomia motivacional diminuiu com o passar dos semestres. Nesse sentido, esses resultados podem ser utilizados para o planejamento de ações que visem o aumento de interesse e de motivação dos estudantes.

Carmo (2014) analisou a motivação dos estudantes do Curso de Bacharelado em Ciências Contábeis nas modalidades presencial e a distância, tendo como base a Teoria da Autodeterminação. O autor aponta como principal contribuição do estudo o fato de a modalidade a distância não apresentar resultados expressivos de autodeterminação, demonstrando autonomia mediana, voltada principalmente para a aquisição de reconhecimento social.

Silva (2014) desenvolveu um trabalho relacionando motivação com a Educação Musical na perspectiva da teoria da Autodeterminação. Esse trabalho envolveu 71 estudantes do curso de Licenciatura em Música da Universidade Federal da Bahia e apresentou como objetivo averiguar as orientações motivacionais, bem como os fatores que influenciam os tipos de motivação. Segunda a autora, esses estudantes apresentam motivação autônoma de qualidade, estando situados entre a motivação extrínseca por regulação integrada e identificada e a motivação intrínseca.

Araújo (2015) realizou um estudo com 380 estudantes do curso de Licenciatura em Música, de quatro universidades públicas do Nordeste. Com base na teoria da Autodeterminação, o estudo teve como objetivo averiguar a qualidade motivacional dos licenciandos, e os resultados evidenciaram maiores médias para as formas mais autodeterminadas em detrimento da desmotivação e de formas menos autônomas de motivação.

Vasconcelos, Freire e Sercundes (2016) realizaram um trabalho com 17 estudantes do curso de Bacharelado em Ciências Contábeis na modalidade a distância com o objetivo de identificar os desafios da aprendizagem autônoma, tendo como referência a Teoria da Autodeterminação. Os resultados evidenciaram a presença de motivação autônoma entre os participantes, prevalecendo a motivação extrínseca por regulação integrada, seguida pela motivação intrínseca e regulação identificada.

Lopes (2018) desenvolveu um trabalho com 130 estudantes matriculados nos cursos de EaD de uma Instituição de Ensino Superior privada, com o objetivo de identificar os fatores extrínsecos e intrínsecos que interferem na motivação de aprendizagem. Os resultados apontaram para o predomínio da motivação 
extrínseca por regulação integrada e motivação intrínseca, evidenciando a elevada motivação dos participantes.

Canuto (2018) realizou um estudo com 227 estudantes do curso de Tecnologia em Hotelaria do Instituto Federal de Educação, Ciência e Tecnologia do Ceará com o intuito de identificar os fatores intrínsecos e extrínsecos que motivam a permanência dos estudantes no curso, tendo como base a Teoria da Autodeterminação. De acordo com o autor, os resultados apontam para uma motivação mais autônoma entre os participantes.

A literatura apresenta, também, embora em menor quantidade, trabalhos relacionados à motivação e à formação inicial de professores. Boruchovitch (2008) desenvolveu um estudo com 225 estudantes de cursos de formação de professores de duas Instituições, sendo uma pública e outra da rede particular. Nesse estudo, a autora destaca alguns resultados, tais como: as mulheres apresentaram médias mais elevadas de motivação intrínseca e extrínseca quando comparadas aos homens; as médias de motivação dos estudantes das universidades públicas foram maiores em relação às universidades privadas; a motivação dos estudantes aumentou com o avançar da idade; estudantes que estavam no início e no término do curso apresentaram maiores médias de motivação se comparados aos estudantes que estavam cursando semestres intermediários, entre outros.

Em relação à formação de professores de Química, Toledo et al. (2018) realizaram um trabalho sobre a motivação para tornar-se professor. Os autores apontam que os estudantes permanecem no curso devido a três fatores: reconhecem a importância da profissão docente, sentem prazer pela atividade docente e concebem esse momento como uma missão de vida. Os autores enfatizam ainda que esses dados podem subsidiar ações e estratégias contra a evasão dos estudantes.

Bego e Ferrari (2018) desenvolveram uma pesquisa buscando levantar as motivações dos estudantes para cursar Licenciatura em Química. A pesquisa foi realizada nos quatro Câmpus da UNESP, localizados nos municípios de Araraquara, Bauru, Presidente Prudente e São José do Rio Preto. Um dado interessante desse trabalho foi em relação à atratividade da carreira. Segundo os autores, as motivações dos ingressantes de 2013 foram basicamente intrínsecas, com poucas motivações proporcionadas por fatores extrínsecos. Assim, a maioria optou pelo curso pelo prazer e pela satisfação da profissão docente.

É importante ressaltar a existência de poucos trabalhos na literatura relacionando motivação e cursos de Licenciatura em Química. Diante desse contexto, levando em consideração a necessidade de novos trabalhos mediante a escassez de estudos sobre essa temática, principalmente no Ensino Superior e, mais especificamente, em relação à formação de professores de Química, este trabalho apresenta como objetivo levantar o perfil motivacional dos ingressantes de 2019 nos cursos de Licenciatura em Química do Instituto Federal de Educação, Ciência e Tecnologia de São Paulo (IFSP), de acordo com a teoria da Autodeterminação. Espera-se que os resultados obtidos neste estudo possam subsidiar estratégias/ações visando à aprendizagem e à permanência dos estudantes no curso. 


\section{METODOLOGIA}

Esta pesquisa apresenta métodos mistos de análise de dados, sendo, portanto, de caráter quali-quatitativa, uma vez que utiliza um questionário para a coleta de dados e parte dos resultados são descritos na forma de números. No entanto, a pesquisa não é apenas quantitativa, uma vez que analisa também os significados atribuídos por pessoas a eventos ou fatos, além das próprias interações entre indivíduos. Isso permite complementaridade de enfoques na análise dos dados. $O$ trabalho também pode ser classificado como pesquisa do tipo exploratória, com foco em viabilizar a familiaridade da comunidade de Ensino com o perfil motivacional de um grupo de estudantes de licenciatura em química, o que possibilita futuras pesquisas sobre o tema.

\section{PARTICIPANTES}

Foram convidados para participar deste estudo os ingressantes de 2019, do curso de Licenciatura em Química do IFSP. É importante ressaltar que a Instituição apresenta 36 câmpus espalhados pelo Estado de São Paulo e a Licenciatura em Química está presente em nove deles: Barretos, Capivari, Catanduva, Matão, São João da Boa Vista, São José dos Campos, São Paulo, Sertãozinho e Suzano. Para fins de análise, esses câmpus não serão identificados com os nomes, ao longo do texto.

É importante observar que no Câmpus São João da Boa Vista, o curso é de Licenciatura em Ciências Naturais com habilitação em Química ou Física e, nesse caso, todos os ingressantes foram convidados a participar da pesquisa, uma vez que a escolha da habilitação se dá nos anos posteriores ao ingresso. Também é importante mencionar que o Câmpus Matão oferta a Licenciatura em Química em dois períodos (matutino e noturno). Como os resultados foram semelhantes nos dois períodos, optou-se por agrupar os dados desse câmpus em um único resultado.

Participaram da pesquisa 176 licenciandos em Química, sendo 117 (66,5\%) mulheres e 59 (33,5\%) homens, distribuídos na seguinte faixa etária: 94 estudantes $(53,4 \%)$ até 19 anos, $53(30,1 \%)$ entre 20 e 25 anos, $16(9,1 \%)$ entre 26 e 30 anos, e $12(6,8 \%)$ acima de 31 anos de idade. A maioria é branca com $115(65,3 \%)$ participantes, seguida por pardos/amarelos/indígenas com 45 (25,6\%) participantes e $16(9,1 \%)$ participantes negros. A média da renda familiar dos participantes foi entre 2 a 3 salários mínimos. A maioria (70,5\%) é formada por estudantes que não exercem atividade remunerada, dedicando seu tempo exclusivamente aos estudos.

\section{INSTRUMENTO DE COLETA DE DADOS}

O questionário utilizado para este estudo foi composto de duas partes, sendo a primeira relacionada ao levantamento das condições socioeconômicas dos participantes e a segunda à motivação dos ingressantes de 2019 nos cursos de Licenciatura em Química do IFSP. Para averiguar o perfil motivacional dos participantes utilizou-se a versão brasileira da EMA proposta e validada por Guimarães e Bzuneck (2008). Esse questionário foi utilizado em trabalhos que visavam levantar o perfil motivacional de universitários (SOUZA, 2008; 
ENGELMANN, 2010; LEAL; MIRANDA; CARMO, 2013; CARMO, 2014; ARAÚJO, 2015; CANUTO, 2018).

A EMA de Guimarães e Bzuneck (2008) refere-se a um questionário de autorrelato contendo 31 afirmações que visam identificar os diferentes tipos de motivação, sendo agrupadas em sete categorias: desmotivação, motivação extrínseca por regulação externa por frequência às aulas (MER Frequência), motivação extrínseca por regulação externa por recompensas sociais (MER Recompensas sociais), motivação extrínseca por regulação introjetada (MER Introjetada), motivação extrínseca por regulação identificada (MER Identificada), motivação extrínseca por regulação integrada (MER Integrada) e motivação intrínseca (MI).

Cada afirmação apresentava uma escala do tipo Likert que variava de 1 a 7 pontos, no qual 1 correspondia a "discordo totalmente" e 7 a "concordo plenamente". O questionário foi proposto para avaliar a motivação de universitários, tendo como questão norteadora "Por que venho à Universidade?". Após os testes estatísticos, a EMA proposta por Guimarães e Bzuneck (2008) teve duas afirmações excluídas; no entanto, o presente trabalho optou pela utilização do questionário completo, conforme proposto inicialmente.

\section{PROCEDIMENTO}

Todos os dados foram coletados presencialmente por meio da aplicação de um questionário impresso disponível no anexo presente no final deste artigo. Este estudo foi submetido ao Comitê de Ética (CAAE: 14213819.9.3001.5473, e aprovado em 27/06/2019) pela Instituição onde foram coletados os dados.

A aplicação foi feita por um dos pesquisadores em horário de aula. Durante essa etapa, esse pesquisador explicou aos participantes os objetivos da pesquisa, apresentou e discutiu o termo de consentimento livre e esclarecido, deixando claro que a participação não era obrigatória, que não precisavam identificar-se e que os dados seriam tratados com total sigilo. Além disso, foi informado para todos os participantes que a participação na pesquisa não influenciaria em suas avaliações nas disciplinas do curso. Após sanar as dúvidas, o pesquisador solicitou o preenchimento do questionário, o que levou em média 30 minutos.

\section{ANÁLISE DE DADOS}

O estudo envolveu a realização de análises estatísticas descritivas dos itens, tais como a média, a variância, o teste de confiabilidade e a análise de correlação. Os dados foram analisados à luz da Teoria da Autodeterminação e os resultados foram relacionados com os trabalhos disponíveis na Literatura.

\section{RESULTADOS}

Pelo fato de utilizar um questionário validado e amplamente utilizado para investigar a motivação de universitários no cenário nacional, não foi objetivo deste trabalho reproduzir todos os testes estatísticos realizados por Guimarães e 
Bzuneck (2008). No entanto, alguns deles serão apresentados visando buscar aproximações e/ou distanciamentos com o referencial utilizado.

Em relação à confiabilidade dos dados referentes à EMA, este trabalho apresentou um Alfa de Cronbach de 0,78. Para Freitas e Rodrigues (2005), valores de alfa entre $0,75 \alpha \leq 0,90$ são considerados de alta confiabilidade. Portanto, os dados deste trabalho apresentam um alto grau de confiabilidade do ponto de vista estatístico.

\section{PERFIL MOTIVACIONAL DOS INGRESSANTES POR CÂMPUS}

Os perfis motivacionais dos ingressantes de 2019 dos cursos de Licenciatura em Química do IFSP estão apresentados na Figura 2:

Figura 2 - Perfil motivacional dos ingressantes

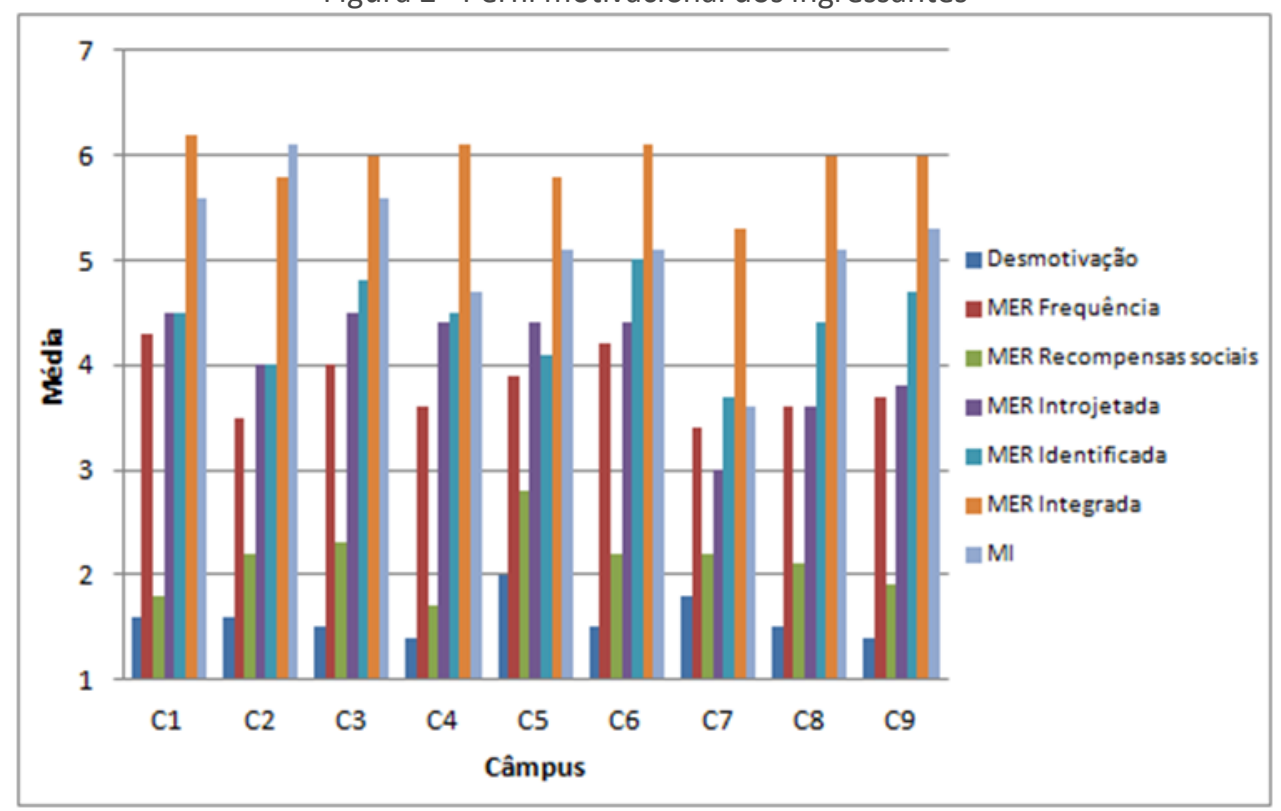

Fonte: Autoria própria (2020).

As questões foram agrupadas em sete categorias. Os resultados apresentados referem-se às médias simples obtidas por meio das respostas dos licenciandos. Por meio da Figura 2, foi possível constatar que, dentro de cada categoria, os valores das médias variaram pouco entre os câmpus. Isso nos permite afirmar que o perfil motivacional dos diferentes grupos de alunos é semelhante nas diversas regiões onde se encontram os cursos do IFSP, a despeito das distâncias geográficas que separam esses alunos e das possíveis diferenças culturais. Dos cerca de 500 quilômetros que separam, por exemplo, Barretos de São José dos Campos, no Estado de São Paulo, existem diversas questões regionais da cultura e de mercado de trabalho que poderiam influenciar a motivação dos estudantes. No entanto, o que observamos com os dados é que essas diferenças são mínimas.

As menores médias foram obtidas respectivamente nas categorias Desmotivação e MER Recompensas sociais. A categoria MER Frequência apareceu com a terceira menor média nos câmpus analisados, exceto no câmpus C7. 
Na categoria Desmotivação, por exemplo, foram apresentadas afirmações como: "Sinceramente, eu não sei por que venho à Universidade"; "Eu realmente sinto que estou perdendo meu tempo na universidade"; "Eu já tive boas razões para vir à universidade, mas, agora, tenho dúvidas sobre continuar"; "Eu não vejo que diferença faz vir à universidade", entre outras afirmações. Para a segunda categoria com menor média, foram apresentadas afirmações tais como: "Venho à universidade para não ficar em casa"; "Venho à universidade porque enquanto estiver estudando não preciso trabalhar", "Ver meus amigos é o principal motivo pelo qual venho à universidade". É importante ressaltar que, para essas categorias, são desejáveis médias próximas a 1, ou seja, precisa estar próximo da total discordância das afirmações. Portanto, valores baixos para essas categorias indicam um perfil autodeterminado de motivação.

Em contrapartida, a categoria MER Integrada apresentou as maiores médias, exceto para o Câmpus C2, no qual a maior média ficou na categoria MI. A segunda maior média ficou por conta da categoria $\mathrm{MI}$, que prevaleceu em 7 dos 9 câmpus. As categorias MER Introjetada e MER Identificada apresentaram valores bem próximos entre si nos diferentes câmpus.

Na categoria que apresentou a maior média - a MER Integrada - foram apresentadas afirmações do tipo "Porque estudar amplia os horizontes"; "Porque o acesso ao conhecimento se dá na universidade"; "Venho à universidade porque é isso que escolhi para mim", e outras afins. Na categoria que apresentou a segunda maior média, MI, as afirmações apresentadas foram "Pelo prazer que tenho quando me envolvo em debates com professores interessantes"; "porque para mim a universidade é um prazer"; "porque gosto muito de vir à Universidade". Para essas categorias são desejáveis médias próximas a 7, ou seja, é preciso que os participantes concordem totalmente com essas afirmações. Nesse sentido, médias elevadas para essas categorias indicam um perfil autodeterminado dos participantes.

Com isso, a partir da constatação de valores baixos (discordância) para afirmativas de Desmotivação e MER Recompensas Sociais, somados ao resultado de valores altos (concordância) para afirmativas de MI e MER Integrada, entendemos que ambos os subgrupos de dados apontam na direção de uma motivação autodeterminada para esse grupo de alunos. Três das categorias descritas em nosso trabalho (MER Frequência, MER Introjetada e MER Identificada) apresentam valores médios próximos a 4. Numa escala de 1 a 7 , o valor 4 representa a possibilidade de não concordar nem discordar da afirmativa, o que será discutido mais adiante, com o apoio dos dados de variância.

Além da média, foram calculadas as variâncias dos itens, que se referem a uma medida de dispersão em relação à média. Assim, quanto menor a variância, mais próximos os valores estão em relação à média.

Em relação à variância dos itens, foi possível constatar valores similares entre os câmpus. A categoria Desmotivação, por exemplo, apresentou menor variância em sete dos nove câmpus. O mesmo ocorreu na categoria MER Integrada, que apresentou a segunda menor variância entre os câmpus. Nesses casos, as respostas dos estudantes oscilaram pouco em relação à média. É importante observar que as menores variâncias coincidem, nesses casos, com as respostas de concordância e discordância de itens que apontam, ambos, em direção a uma 
motivação autodeterminada, o que reflete uma visão mais uniforme dos alunos em relação a essas categorias.

Em oito dos nove câmpus constatou-se que os maiores valores de variância estavam nas categorias MER Frequência e MER Identificada. Nessas categorias, portanto, foi possível observar maior quantidade de respostas que se afastaram da média, ou seja, respostas mais divergentes entre si. As demais categorias apresentaram valores semelhantes entre os câmpus. Novamente, é importante observar que as maiores variâncias coincidem, nesses casos, com as respostas de concordância e discordância que apontam em direção a uma opinião não clara sobre o tema. Nesse sentido, isto reflete as múltiplas visões dos estudantes sobre essas categorias. Apesar de a média resultar em ausência de concordância ou de discordância, a maior variância nos ajuda a compreender que, na realidade, os alunos concordaram com as afirmativas ou discordaram delas, mas não de maneira uniforme.

De modo geral, foi possível observar diferenças consideráveis para os valores de variância entre as categorias. Em ordem crescente de variância, foi verificado menor valor para a Desmotivação (valores entre 0,8 e 3,0, com valor médio de 1,6), seguida pela MER Integrada (1,1 a 3,1 e valor médio 2,0), MI (0,9 a 4,3 e valor médio 2,6), MER Recompensas Sociais (1,8 a 4,7 e valor médio 2,8), MER Introjetada (3,0 a 4,4 e valor médio 3,6), MER Identificada (2,7 a 4,9 e valor médio 3,9), e maior valor para MER Frequência (3,7 a 5,3 e valor médio 4,3).

Levando em consideração as médias e as variâncias, constatou-se uma similaridade e homogeneidade dos resultados. Não houve nenhum curso com o perfil motivacional que destoasse de forma significativa dos demais e, assim, optamos por agrupar os resultados dos diferentes câmpus em apenas um conjunto visando traçar o perfil motivacional dos ingressantes dos cursos de Licenciatura em Química do IFSP de 2019, que será apresentado no tópico a seguir.

\section{PERFIL MOTIVACIONAL DOS INGRESSANTES DO IFSP}

O IFSP é um grande centro de formação de professores de Química no Estado de São Paulo. Nesse sentido, é muito importante o desenvolvimento de pesquisas visando à formação desses profissionais nessa Instituição.

Um dado que chama atenção é que, para a maioria dos ingressantes (59,7\%), o curso de Licenciatura em Química não foi a primeira opção. No entanto, ao longo do ano letivo, acabaram se identificando com a modalidade e, ao serem questionados onde pretendem atuar futuramente, a maioria $(64,7 \%)$ apontou a docência, seguida pela indústria $(46,0 \%)$, centros de pesquisas $(45,4 \%)$ e em outras áreas $(14,2 \%)$.

Entre os motivos relacionados à escolha do curso apontaram, em primeiro lugar, a afinidade e facilidade com a Química (50,5\%), seguido pelas múltiplas opções do mercado de trabalho $(40,3 \%)$, inspiração em algum professor ao longo da trajetória escolar $(40,3 \%)$, por influência de pessoas próximas, como família e amigos (23,8\%), entre outros motivos. Chama atenção o fato de apenas $4,5 \%$ dos ingressantes terem escolhido o curso pelo prestígio e status da carreira docente e 5,1\% pela remuneração. 
A Figura 3 apresenta o perfil motivacional dos ingressantes dos cursos de Licenciatura em Química do IFSP em comparação com os dados obtidos por Guimarães e Bzuneck (2008), utilizados neste trabalho como referência.

Figura 3: Perfil motivacional dos participantes desse estudo e da referência utilizada

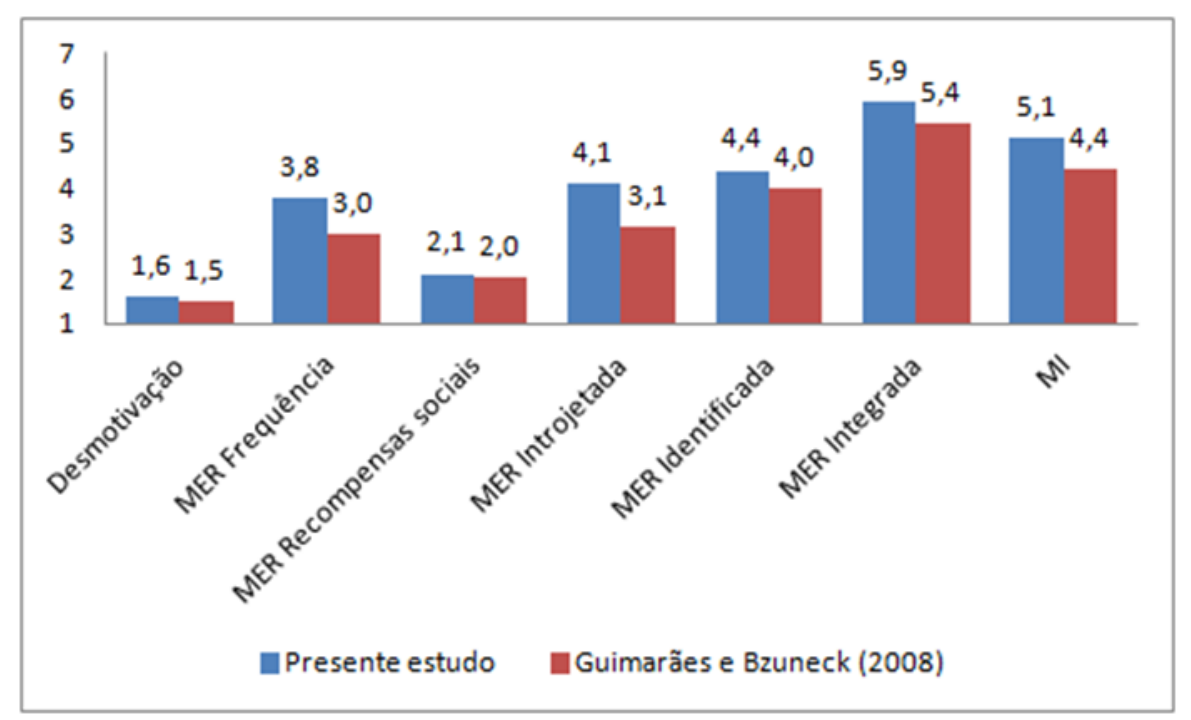

Fonte: Autoria própria (2020).

A partir da Figura 3, foi possível constatar que os ingressantes de 2019 nos cursos de Licenciatura em Química do IFSP apresentaram um perfil de motivação autodeterminado semelhante ao do grupo de indivíduos estudados por Guimarães e Bzuneck (2008), tendo a maior média ocorrida na categoria MER Integrada, seguida pela MI e pela MER Identificada. Por outro lado, as menores médias foram encontradas nas categorias Desmotivação, MER Recompensas sociais, MER Frequência e MER Introjetada. No entanto, os resultados desta pesquisa evidenciaram médias ligeiramente maiores em todas as categorias. Provavelmente, essa diferença ocorreu pelo fato deste estudo envolver apenas ingressantes e, conforme evidenciado em estudos anteriores (LEAL; MIRANDA; CARMO, 2013; BORUCHOVITCH, 2008), estes apresentam maiores índices de motivação.

Embora o curso de Licenciatura em Química não tenha sido a primeira opção para a maioria dos ingressantes, em geral, eles chegaram motivados na Instituição e, apontaram como fatores motivadores, a afinidade com a Química, a possibilidade de poder trabalhar futuramente na área de que gostam, por haver diferentes opções de mercado de trabalho, entre outros. É importante que essa motivação permaneça ao longo do curso e isso pode ser feito por meio de ações adotadas pelas Instituições, como convidar palestrantes de diferentes setores (docência, indústria e centros de pesquisa), incentivar a participação dos estudantes em projetos de ensino, pesquisa e extensão, bem como a participação na organização de eventos, como a Semana da Química, entre outras. Essas ações podem contribuir diretamente para a motivação dos licenciandos, contribuindo para a sua permanência e êxito no curso.

A participação dos licenciandos em diferentes atividades contribui para nutrir as necessidades psicológicas básicas de competência, autonomia e pertencimento, 
promovendo assim, as formas mais autodeterminadas de motivação nos estudantes (RYAN; DECI, 2000b; REEVE, 2006). Nesse sentido, as Instituições, assim como os docentes, assumem um papel importante na manutenção da motivação, podendo contribuir diretamente para a permanência e êxito dos estudantes.

É importante ressaltar que o perfil autodeterminado de motivação verificado neste estudo vai ao encontro de outros trabalhos disponíveis na literatura (ENGELMAN, 2010; SILVA, 2014; ARAÚJO, 2015; VASCONCELOS; FREIRE; SERCUNDES, 2016; LOPES, 2018; CANUTO, 2018).

Desde que satisfaça as necessidades psicológicas, as interações sociais podem promover um maior grau de autorregulação (RYAN; DECl, 2000b). Em contraposição, a ausência dessas condições pode comprometer a motivação autodeterminada dos estudantes, fazendo com que eles cumpram as atividades apenas por pressões externas. Nesse sentido, conhecer o perfil motivacional dos estudantes é muito importante para mantê-los envolvidos com o curso, ao longo do seu processo formativo.

De acordo com Deci e Ryan (1985), todo comportamento humano é intencional, podendo ser autônomo ou controlado. No comportamento autônomo, o indivíduo realiza uma tarefa pela satisfação em executá-la. Essas decisões autônomas foram denominadas autodeterminadas, e como carregam em si um alto grau de autonomia passaram também a ser intituladas de motivação autônoma (REEVE, 2004).

No comportamento controlado, os indivíduos realizam as tarefas mediante o recebimento de recompensas, sendo caracterizado como baixo grau de regulação, do qual fazem parte a MER Externa (neste trabalho desmembrado em duas: MER Frequência e MER Recompensas sociais) e a MER Introjetada. É o caso dos estudantes que realizam as tarefas apenas para não sofrer pressão dos pais ou professores, por exemplo. Pesquisas (REEVE; BOLT; CAI, 1999; RYAN; DECI, 2006) evidenciaram que estudantes com baixo grau de regulação, principalmente a Externa tendem a fugir de desafios, não apresentam iniciativa para a realização das tarefas e estão preocupados em concluir a atividade com rapidez, sem se preocupar com a qualidade. De forma complementar, Bzuneck e Guimarães (2010) apontam que, nessas circunstâncias, os estudantes aprendem menos, principalmente se a atividade envolver conteúdos mais elaborados.

Compreender o tipo de comportamento do estudante é muito importante para o planejamento da Instituição. De acordo com Guimarães e Bzuneck (2008),

\begin{abstract}
A motivação dos estudantes para a aprendizagem é um fenômeno complexo, multideterminado que pode apenas ser inferido, mediante a observação do comportamento, seja em situações reais de desempenho ou de auto-relato. É comum, entre educadores e estudiosos do tema, a valorização do ambiente escolar como importante promotor da motivação e da aprendizagem. No entanto, as intervenções para um problema de tal magnitude não podem ser baseadas no senso comum ou em diretrizes que careçam de respaldo teórico (GUIMARÃES; BZUNECK, 2008, p.111-112).
\end{abstract}

Nesse sentido, o questionário proposto por Guimarães e Bzuneck (2008) e utilizado neste trabalho constituiu um instrumento de autorrelato capaz de fornecer informações importantes para a Instituição a respeito dos cursos de 
Licenciatura em Química, uma vez que todos os câmpus que apresentam esse curso participaram da pesquisa.

Além de apresentar um Alfa de Cronbach confiável, foram realizados testes de correlações entre as categorias. Para Guimarães e Bzuneck (2008) as categorias devem apresentar valores de correlações positivas quando estão próximas entre si no continuum de motivação e correlações negativas entre as extremidades. Não é possível, por exemplo, que a motivação intrínseca aumente com o aumento da desmotivação, ou seja, elas estão situadas nos extremos do continuum e o aumento de um tipo deve ocasionar a diminuição do outro, por isso a correlação negativa. Os dados das correlações verificadas neste estudo estão próximos dos encontrados no trabalho de Guimarães e Bzuneck (2008). Dessa forma, os resultados apontam para evidências da existência do continuum de motivação, sendo que esse instrumento pode ser um importante aliado para levantar o perfil motivacional dos estudantes e, consequentemente contribuir para melhorias nos cursos de formação de professores.

\section{CONSIDERAÇÕES FINAIS}

A motivação está diretamente relacionada ao desempenho acadêmico, bem como a permanência e o êxito dos estudantes no curso. Assim, é muito importante o desenvolvimento de estudos que visam ao levantamento do perfil motivacional, pois, desse modo, é possível planejar ações tendo em vista melhorias nos cursos de formação inicial.

Os dados deste trabalho evidenciaram um perfil autodeterminado de motivação dos ingressantes, ou seja, eles chegam motivados para cursar a Licenciatura em Química, mesmo que essa não tenha sido a primeira opção da maioria. Espera-se que os estudantes mantenham essa motivação ao longo de todo processo formativo, e isso será alcançado se as ações forem planejadas visando o atendimento das necessidades psicológicas básicas de todo indivíduo: competência, autonomia e pertencimento.

O questionário utilizado como instrumento de coleta de dados mostrou-se eficiente e adequado para os objetivos do trabalho. O teste de confiabilidade, aliado ao teste de correlação evidenciaram valores próximos aos da literatura.

É importante ressaltar que existem poucos trabalhos na literatura envolvendo motivação e formação de professores e, mais especificamente, em relação à formação de professores de Química, segundo a Teoria da Autodeterminação. Levando em consideração que o IFSP é um grande centro formador de professores no Estado de São Paulo e que o trabalho abrange todos os Câmpus, este estudo é de grande relevância para a área educacional e para a Instituição. Para que ocorra o desenvolvimento de uma determinada área do conhecimento é muito importante a presença de instrumentos de coleta confiáveis. Espera-se que este trabalho, somado aos demais encontrados na literatura, possa fortalecer a área e contribuir para o seu aprimoramento. 


\title{
Motivation of incoming preservice chemistry teachers at IFSP
}

\begin{abstract}
Many studies have evidenced the importance of motivation in the educational area. There are few works in the literature relating motivation with teacher education. Given the importance of this theme and the lack of works in the literature, this study presents the objective to collect the motivational profile of 2019 incoming preservice chemistry teachers at Federal Institute of Education, Science and Technology of São Paulo (IFSP). The theoretical framework used in this work was the Self-determination Theory, developed by Ryan and Deci (1985). These authors expand the comprehension about extrinsic motivation presenting a motivation continuum, in which an individual may transit through different kinds of motivation within this continuum, as far as it satisfies the basic psychological needs: competence, autonomy and belonging. This research used the questionnaire proposed by Guimarães and Bzuneck (2008) as data collection tool. The application was performed presentially by the researcher during class time and had the participation of 176 preservice chemistry teachers distributed in nine campi. The data were submitted to statistical analysis, such as mean, variance, reliability test and correlation analysis and were compared to works available in literature. The results evidenced a self-determined profile in the participants, prevailing higher means for extrinsic motivation through integrated regulation and intrinsic motivation. The execution of studies such as this one is of great importance for the area because, from them, it is possible to make plans and strategies aiming at the students' permanence and success.
\end{abstract}

KEYWORDS: Preservice teachers. Motivation. Self-determination theory. Chemistry. 


\section{AGRADECIMENTOS}

Ao Instituto Federal de Educação, Ciência e Tecnologia de São Paulo e à Universidade Estadual Paulista Júlio de Mesquita Filho.

\section{REFERÊNCIAS}

ALMEIDA, D. M. S. A motivação do aluno no ensino superior: um estudo exploratório. 2012. Dissertação (Mestrado em Educação) - Universidade Estadual de Londrina, Londrina, 2012.

ANDRADE, M. F.D; SILVA, F.C. Destilação: uma sequência didática baseada na História da Ciência. Química Nova na Escola, São Paulo-SP, v. 40, n. 2, p. 97-105, 2018. Disponível em: http://qnesc.sbq.org.br/online/qnesc40_2/06-RSA-2317.pdf. Acesso em: 16 jan. 2020.

ARAÚJO, I. R. A motivação de licenciandos em música sob a perspectiva da teoria da autodeterminação. 2015. Dissertação (Mestrado em Música) Universidade Federal do Rio Grande do Norte, Natal, 2015.

BEGO, A.M.; FERRARI, T.B. Por que escolhi fazer um curso de licenciatura? Perfil e motivação dos ingressantes da UNESP. Revista Química Nova, v. 41, n. 4, 457467, 2018. Disponível em:

http://static.sites.sbq.org.br/quimicanova.sbq.org.br/pdf/ED20170318.pdf. Acesso em: 10 jan. 2020.

BORUCHOVITCH, E. A motivação para aprender de estudantes em cursos de formação de professores. Educação, Porto Alegre, v. 31, n. 1, p. 30-38, 2008. Disponível em:

http://revistaseletronicas.pucrs.br/ojs/index.php/faced/article/view/2754/2102. Acesso em: 10 jan. 2020.

BZUNECK, J. A. A motivação do aluno: aspectos introdutórios. In: Boruchovitch, E; Bzuneck (org.): A motivação do aluno: contribuições da psicologia contemporânea. 4a ed. Petrópolis, RJ: Vozes, 2009.

BZUNECK, J. A.; BORUCHOVITCH, E. Adolescence and education: Contemporary trend in Brazilian research. In: PAJARES, F.; URDAN, T. (Org.). International perspectives in adolescence. Information Age Publishing: Greenwich, EUA, p. 215-236, 2003.

BZUNECK, J. A.; GUIMARÃES, S.E.R. A promoção da autonomia como estratégia motivacional na escola: uma análise teórica e empírica. In: BORUCHOVITCH, E; BZUNECK, J.A.; GUIMARÃES, S.E.R. (Org.) Motivação para aprender: aplicações no contexto educativo. 2a edição. Ed.Vozes, Petrópolis, RJ; 2010.

CANUTO, V. R. Fatores extrínsecos e intrínsecos que motivam a permanência dos alunos do curso em tecnologia em hotelaria do Instituto Federal de Educação, Ciência e Tecnologia do Ceará com base na teoria da 
autodeterminação. 2018. Dissertação (Mestrado) - Universidade Federal do Ceará, Fortaleza, 2018.

CARMO, C.R.S. Motivação discente no curso de Bacharelado em Ciências Contábeis: um estudo comparativo entre alunos da modalidade presencial e alunos da modalidade a distância. ConTexto, Porto Alegre, v. 14, n. 26, p. 7-18, 2014. Disponível em: https://seer.ufrgs.br/ConTexto/article/view/33841/pdf_13. Acesso em: 16 dez. 2019.

CARVALHO, W.; STANZANI, E.L.; PASSOS, M.M. A motivação no Ensino de Ciências: análise de dez anos de trabalhos apresentados no ENPEC. ACTIO, Curitiba, v. 2, n. 3, p. 97-114, 2017. Disponível em: https://periodicos.utfpr.edu.br/actio/article/view/6820/4630. Acesso em: 26 nov. 2019.

CATANHO, M. Relações entre motivação e aprendizagem no ensino de Química. 2018. Dissertação (Programa de Pós-graduação em Ensino e Processos Formativos) UNESP, São José do Rio Preto, 2018.

CLEMENT, L. Autodeterminação e ensino por investigação: Construindo elementos para promoção da Autonomia em aulas de Física. 2013. Tese. (Programa de Pós-Graduação em Educação Científica e Tecnológica) Universidade Federal de Santa Catarina, Florianópolis, 2013.

CORRÊA, R. G. Estudo do Perfil Motivacional para o Aprendizado de Química. 2009. Dissertação (Mestrado em Química) - Universidade Federal de São Carlos, São Carlos, 2009.

DECI, E.L. The psychology of self-determination. Lexington, MA: Lexington Books, 1980.

DECI, E.L.; RYAN, R.M. Intrinsic motivation and self-determination in human behavior. New York: Plenum Press, 1985.

ENGELMANN, E. A motivação de alunos dos cursos de artes de uma universidade pública do norte do Paraná. Dissertação (Programa de PósGraduação em Educação), Londrina, Paraná, 2010.

FABRI, P.H; GIACOMINI, R.A. Estudo da Motivação do Aluno no Processo de Ensino e Aprendizagem Promovida pelo Uso de Modelos Moleculares, Validado por Meio de Áudio e Vídeo. Química Nova na Escola, São Paulo-SP, v. 40, n. 3, p. 196-208, 2018. Disponível em: http://qnesc.sbq.org.br/online/artigos/09-EQF-4317.pdf Acesso em: 17 dez. 2019.

FREITAS, A. L. P.; RODRIGUES, S. G. A avaliação da confiabilidade de questionários: uma análise utilizando o coeficiente alfa de Cronbach. SIMPEP. Bauru-SP, 2005. Disponível em: https://www.researchgate.net/publication/236036099_A_avaliacao_da_confiabil idade_de_questionarios_uma_analise_utilizando_o_coeficiente_alfa_de_Cronba ch. Acesso em: 17 dez. 2019. 
GUIMARÃES, S.E.R.; BZUNECK, J.A. Propriedades psicométricas de um instrumento para avaliação da motivação de universitários. Ciências \& Cognição, v. 13, p.101-113, 2008. Disponível em: http://www.cienciasecognicao.org/pdf/v13/m318210.pdf. Acesso em: 15 out. 2019.

KASSEBOEHMER, A.C.; FERREIRA, L.H. O método investigativo em aulas teóricas de Química: estudo das condições da formação do espírito científico. Revista Electrónica de Enseñanza de las Ciencias. v. 12, n. 1, 144-168, 2013. Disponível em: http://reec.uvigo.es/volumenes/volumen12/REEC_12_1_8_ex612.pdf. Acesso em: 17 dez. 2019.

LEAL, E.A.; MIRANDA, G.J.; CARMO, C.R.S. Teoria da Autodeterminação: uma Análise da Motivação dos Estudantes do Curso de Ciências Contábeis. Revista Contabilidade \& Finanças. USP, São Paulo, v. 24, n. 62, p. 162-173, 2013. Disponível em: http://www.scielo.br/scielo.php?script=sci_abstract\&pid=S151970772013000200007\&lng=en\&nrm=iso\&tlng=pt. Acesso em: 20 dez. 2019.

LOPES, T.V. Fatores intrínsecos e extrínsecos que interferem na motivação de aprendizagem em estudantes em EaD. 2018. Dissertação (Mestrado Profissional em Controladoria e Finanças). Universidade Presbiteriana Mackenzie, São Paulo, 2018.

LOURENÇO, A.A.; PAIVA, M.O.A. A motivação escolar e o processo de aprendizagem. Ciências \& Cognição. v. 15. n. 2, p. 132-141, 2010. Disponível em http://pepsic.bvsalud.org/scielo.php?script=sci_arttext\&pid=S180658212010000200012. Acesso em: 16 jan. 2020.

MARCONI, M. A.; LAKATOS, A. M. Fundamentos de metodologia científica, $8^{a}$ ed., São Paulo: Editora Atlas, 2017.

PARRA, K. N., \& KASSEBOEHMER, A. C. Palestras de Divulgação Científica de Química: Contribuições para a Crença na Autoeficácia de Estudantes do Ensino Médio. Revista Brasileira de Pesquisa em Educação em Ciências, v. 18, n.1, p. 205-237, 2018. Disponível em:

https://periodicos.ufmg.br/index.php/rbpec/article/view/4703/3014. Acesso em: 12 jan. 2020.

REEVE, J. Motivação \& Emoção. Rio de Janeiro: LTC, 2006.

REEVE, J.; BOLT, E.; CAI, Y. Autonomy-supportive teachers: How they teach and motivate students. Journal of Educational Psychology, 91, 537-548, 1999.

Disponível em:

https://pdfs.semanticscholar.org/f30c/0a522140d4a7d5288c60b429789647eab0 b5.pdf. Acesso em: 24 nov. 2019.

ROSSIERI, R. A. Estudo acerca da motivação e aprendizagem a partir de uma implementação de uma sequência didática de química orgânica. 2017.

Dissertação (Mestrado em Ensino de Ciências Humanas, Sociais e da Natureza) - 
RYAN, R.M.; DECI, E.L. Self-Determination theory and the facilitation of Intrinsic motivation, social development, and Well-Being. American Psychologist, v. 55, n.1, p. 68-78, 2000a.Disponível em:

https://selfdeterminationtheory.org/SDT/documents/2000_RyanDeci_SDT.pdf. Acesso em: 24 nov. 2019.

RYAN, R. M.; DECI, E. L. Intrinsic and extrinsic motivations: Classic definitions and new directions. Contemporary Educational Psychology, v. 25, n.1, p. 54-67, 2000b. Disponível em https://www.sciencedirect.com/science/article/pii/S0361476X99910202. Acesso em 25 nov. 2019.

RYAN, R. M.; DECI, E. L. Self-Regulation and the problem of human autonomy: Does Psychology need choice, Self-determination, and will? Journal of Personality, v. 74, n.6, p.1557-1585, 2006. Disponível em: https://selfdeterminationtheory.org/SDT/documents/2006_RyanDeci_SelfRegulationProblemofHumanAutonomy.pdf. Acesso em: 25 nov. 2019.

SILVA, V. M.; RICO, E. P.; SOUZA, D.; OLIVEIRA, D. L. Impacto do uso de estratégias investigativas sobre as emoções e a motivação dos alunos e as suas concepções de ciência e cientista. Revista Electrónica de Enseñanza de las Ciencias. v. 14, n. 1, p.17-34, 2015. Disponível em: http://reec.uvigo.es/volumenes/volumen14/REEC_14_1_2_ex888.pdf. Acesso em 16 dez. 2019.

SEVERO, I.R.M.; KASSEBOEHMER, A.C. Motivação dos alunos: reflexões sobre o perfil motivacional e a percepção dos professores. Revista Química Nova na Escola, v. 39, n. 1, p. 75-82, 2017. Disponível em: http://qnesc.sbq.org.br/online/qnesc39_1/12-EQF-89-15.pdf. Acesso em: $16 \mathrm{dez}$. 2019.

DANTAS, T. Educação Musical e Motivação: um estudo sobre a formação de professores a partir da teoria da autodeterminação. 2014. 145 f. Tese (Educação Musical). Escola de Música, Programa de Pós-Graduação Em Música, Universidade Federal da Bahia, Salvador. 2014.

SOBRAL, D. T. Motivação do Aprendiz de medicina: uso da escala de motivação acadêmica. Psicologia: Teoria e Pesquisa. v. 19, n.1, p. 25-31, 2003. Disponível em http://www.scielo.br/pdf/ptp/v19n1/a05v19n1. Acesso em 26 out. 2019.

SOUZA, I. C. A perspectiva de tempo futuro e a motivação de estudantes de pedagogia. 2008. Dissertação (Programa de Pós-Graduação em Educação), Universidade Estadual de Londrina, Londrina, PR, 2008.

TOLEDO, E.J.L.; COUTINHO, H.N.; GALDINO, A.S.; MACHADO, V.L.P.; MONTEIRO, F.S. A motivação para ser professor: aspectos quantitativos e qualitativos. XIX Encontro Nacional de Ensino de Química. Rio Branco, AC, Brasil, 2018. Disponível em: https://periodicos.ufac.br/index.php/SciNat/article/view/2495. Acesso em: 16 jan. 2020. 
VALLERAND, R.J.; PELLETIER, L.G.; BLAIS, M.R.; BRIÈRE, N.M.; SENÉCAL, C. E VALLIÈRES, E.F. The academic motivation scale: A measure of intrinsic, extrinsic, and amotivation in education. Educational and Psychological Measurement, 52, 1003-1017, 1992. Disponível em:

https://www.researchgate.net/publication/209836138_The_Academic_Motivati on_Scale_A_Measure_of_Intrinsic_Extrinsic_and_Amotivation_in_Education. Acesso em: 25 nov. 2019.

VASCONCELOS, A.L.F.S. FREIRE, D.R.; SERCUNDES, J.S. Desafios de aprendizagem autônoma dos estudantes de ciências contábeis do curso de educação a distância a luz da teoria da autodeterminação. Revista Brasileira de Contabilidade, n.222, p.55-65, 2016.Disponível em:

http://rbc.cfc.org.br/index.php/rbc/article/view/1488/1064. Acesso em: 16 dez. 2019.

\section{ANEXO: ESCALA DE MOTIVAÇÃO ACADÊMICA UTILIZADA NESTE TRABALHO}

\section{Parte II: Escala de Motivação Acadêmica (EMA) de Universitários}

Este questionário é amplamente utilizado na área de Psicologia para levantar os perfis motivacionais de universitários. Foi proposto e validado por Guimarães e Bzuneck (2008). Para cada item, tem-se uma escala de Likert que varia de 1 a 7 , onde 1 significa discordo plenamente e 7 concordo plenamente. Quanto mais próximo de 7, maior a concordância com a afirmação. O participante deverá assinalar uma alternativa para cada item visando responder a questão norteadora do questionário: Por que venho à Universidade?

\begin{tabular}{ccccccc}
\multicolumn{5}{c}{ Aumenta o grau de concordância em relação à afirmação } \\
$\begin{array}{c}\text { Discordo } \\
\text { plenamente }\end{array}$ & 2 & 3 & 4 & 5 & 6 & 7 \\
$\begin{array}{c}\text { Nem concordo } \\
\text { enem Discordo }\end{array}$ & & $\begin{array}{c}\text { Concordo } \\
\text { plenamente }\end{array}$
\end{tabular}

\begin{tabular}{|l|l|l|l|l|l|l|l|}
\hline \multicolumn{1}{|c|}{ QUESTÕES } & \multicolumn{5}{|c|}{ NÍVEIS DA ESCALA } \\
\cline { 2 - 8 } & 1 & 2 & 3 & 4 & 5 & 6 & 7 \\
\hline $\begin{array}{l}\text { 01. Sinceramente, eu não sei por que venho à } \\
\text { Universidade. }\end{array}$ & & & & & & \\
\hline $\begin{array}{l}\text { 02. Venho à universidade porque acho que a } \\
\text { frequência deve ser obrigatória. }\end{array}$ & & & & & & \\
\hline $\begin{array}{l}\text { 03. Venho à universidade para não receber } \\
\text { faltas. }\end{array}$ & & & & & & \\
\hline $\begin{array}{l}\text { 04. Pelo prazer que tenho quando me envolvo } \\
\text { em debates com professores interessantes. }\end{array}$ & & & & & & \\
\hline $\begin{array}{l}\text { 05. Venho à universidade para provar a mim } \\
\text { mesmo que sou capaz de completar meu curso. }\end{array}$ & & & & & & & \\
\hline 06. Venho à universidade para não ficar em casa. & & & & & & & \\
\hline $\begin{array}{l}\text { 07. Eu realmente sinto que estou perdendo meu } \\
\text { tempo na universidade. }\end{array}$ & & & & & \\
\hline
\end{tabular}




\section{QUESTÕES}

08. Venho porque é isso que esperam de mim.

09. Eu já tive boas razões para vir à universidade, mas, agora, tenho dúvidas sobre continuar.

10. Para mostrar a mim mesmo que sou uma pessoa inteligente.

11. Venho à universidade porque a presença é obrigatória.

12. Porque a educação é um privilégio.

13. Eu não vejo por que devo vir à universidade.

14. Venho à universidade para conseguir o diploma.

15. Venho à universidade porque quando eu sou bem sucedido me sinto importante.

16. Eu não sei, eu não entendo o que estou fazendo na universidade.

17. Porque para mim a universidade é um prazer.

18. Porque o acesso ao conhecimento se dá na universidade.

19. Eu não vejo que diferença faz vir à universidade.

20. Porque quero mostrar a mim mesmo que posso ser bem sucedido nos meus estudos.

21. Porque gosto muito de vir à universidade.

22. Por que acho que a cobrança de presença é necessária para que os alunos levem o curso a sério.

23. Quero evitar que as pessoas me vejam como um aluno relapso.

24. Venho à universidade porque a frequência nas aulas é necessária para a aprendizagem.

25. Caso a frequência não fosse obrigatória poucos alunos assistiriam às aulas.

26. Porque estudar amplia os horizontes.

27. Venho à universidade porque é isso que escolhi para mim.

28. Pelo investimento material que faço para poder estudar.

29. Venho à universidade porque enquanto estiver estudando não preciso trabalhar.

30. Ver meus amigos é o principal motivo pelo qual venho à universidade.

\begin{tabular}{|c|c|c|c|c|c|c|}
\hline \multicolumn{1}{|c|}{ NÍVEIS DA ESCALA } \\
\hline 1 & 2 & 3 & 4 & 5 & 6 & 7 \\
\hline
\end{tabular}

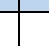

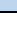

$+\mathbf{x}$

a

$+5$

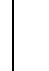




\section{QUESTÕES}

31. Venho à universidade porque meus pais me obrigam.

Recebido: 01 jun. 2020

Aprovado: 22 out. 2020

DOI: $10.3895 /$ actio.v5n3.11563

Como citar:

OLIVEIRA, R.C.; GOIS, J. Motivação de ingressantes de licenciatura em química no IFSP. ACTIO, Curitiba, v. 5, n. 3, p. 1-23, set./dez. 2020. Disponível em: <https://periodicos.utfpr.edu.br/actio>. Acesso em: XXX Correspondência:

Ricardo Castro de Oliveira

Av. Pastor José Dutra de Moraes, 239 - Distrito Industrial Antônio Zácaro, Catanduva, SP, Brasil.

Direito autoral: Este artigo está licenciado sob os termos da Licença Creative Commons-Atribuição 4.0

Internacional.
(c). 